\title{
A DFT Study of CoMoS and NiMoS Catalysts: from Nano-Crystallite Morphology to Selective Hydrodesulfurization
}

\author{
E. Krebs ${ }^{1}, 2$, A. Daudin ${ }^{3}$ and P. Raybaud ${ }^{3 *}$ \\ 1 Institut français du pétrole, IFP, Direction Chimie et Physico-Chimie appliquées, 1-4 avenue de Bois-Préau, 92852 Rueil-Malmaison Cedex - France \\ 2 Université Pierre et Marie Curie, Laboratoire de Chimie Théorique, UMR 7616, 3 rue Galilée, 94000 Ivry-sur-Seine - France \\ 3 Institut français du pétrole, IFP, Direction Catalyse et Séparation, Rond-point de l'échangeur de Solaize, BP 3, 69360 Solaize - France \\ e-mail: emmanuel.krebs@cea.fr - antoine.daudin@ifp.fr - pascal.raybaud@ifp.fr \\ * Corresponding author
}

Résumé - Étude DFT des catalyseurs CoMoS et NiMoS : de la morphologie des nano-cristallites à l'hydrodésulfuration sélective - Cet article présente des résultats récents obtenus dans des études utilisant la théorie de la fonctionnelle de la densité (DFT) pour la caractérisation à l'échelle atomique des phases actives $\mathrm{Co}(\mathrm{Ni}) \mathrm{MoS}$ utilisées en catalyse d'hydrodésulfuration (HDS) sélective. L'effet des conditions du milieu réactionnel sulfo-réducteur sur la stabilité et la nature des sites actifs localisés au bord des nano-cristallites $\mathrm{Co}(\mathrm{Ni}) \mathrm{MoS}$ est mis en évidence. En combinant les calculs DFT et un modèle thermodynamique, il apparaît que la teneur en promoteur sur les bords des cristallites en conjonction avec la morphologie des cristallites dépend des conditions sulfo-réductrices. Nous montrons ensuite comment la nature des sites actifs $\mathrm{Co}(\mathrm{Ni}) \mathrm{Mo}$ influence l'HDS sélective de molécules soufrées légères (alkylthiophènes) vis-à-vis de l'hydrogénation ( $\mathrm{HydO}$ ) des oléfines légères (alkyl-butènes). La combinaison des calculs DFT d'adsorption de deux molécules modèles (2-méthyl-thiophène et 2,3-diméthyl-but-1-ène) avec la modélisation cinétique de la sélectivité HDS/HydO permet de proposer une explication de l'origine de cette sélectivité basée sur la compétition d'adsorption des réactifs.

\begin{abstract}
A DFT Study of CoMoS and NiMoS Catalysts from Nano-Crystallite Morphology to Selective Hydrodesulfurization - This paper reports an overview of recent DFT studies on the atomic scale characterization of $\mathrm{Co}(\mathrm{Ni}) \mathrm{MoS}$ active phases used in selective hydrodesulfurization (HDS) catalysis. A peculiar attention is paid to the effect of the sulfo-reductive reaction conditions on the stability and nature of the active sites present at the edges of the Co(Ni)MoS nano-crystallites. Combining DFT calculations and a thermodynamic model, it is shown that the promoter content at the crystallite edges in conjunction with the crystallite morphology may change with the sulfo-reductive conditions. We then show how the nature of the Co(Ni)MoS active sites impact the selective HDS of light sulfur compounds (alkylthiophene) versus olefin hydrogenation (alkylbutene). Combining DFT calculations of the adsorption of two relevant model molecules (2-methylthiophene and 2,3-dimethylbutene) with the kinetic modelling of HDS/HydO selectivity, we propose an explanation on the origin of the selectivity based on the competitive adsorption of reactants.
\end{abstract}




\section{INTRODUCTION}

Due to ever stronger environmental concerns, the production of cleaner fuels by catalytic chemical processes (such as hydrodesulfurization, hydrocracking, hydrogenation, etc.) remains a major concern of the refining industry. The challenges for research in the area of heterogeneous catalysis are to provide highly active and selective catalysts for important reactions such as hydrodesulfurization (HDS), i.e. the removal of sulfur from organic molecules under hydrogen pressure.

The industrial catalyst is made of a transition metal sulfide active phase (mixed CoMoS or NiMoS phases) dispersed on $\gamma$-alumina, which is a metastable polymorph of alumina widely used as a catalytic support in the refining industry [1]. Up to now, numerous experimental techniques have been employed to better characterize the catalytically "CoMoS" or "NiMoS" active phases [2, 3]. Experimental techniques involved in the characterization of these complex phases consist of transition electron microscopy (TEM) [4, 5], X-ray photoelectron spectroscopy (XPS) [6-9], Mössbauer spectroscopy [10-12], laser Raman spectroscopy [5, 13], extended X-ray absorption fine structure (EXAFS) [14-18], and IR spectroscopy $[19,20]$. These techniques furnished many detailed features of the so-called $\mathrm{Co}(\mathrm{Ni}) \mathrm{MoS}$ active phase made of $\mathrm{MoS}_{2}$ layers with a stacking close to 1 [21] and nanometer sizes (less than $30 \AA$ ), "decorated" by Co or Ni at the edges. While Mössbauer spectroscopy [10-12] and XPS [6-9] revealed the specific signature of Co atoms engaged in the new CoMoS phase, EXAFS gave relevant insights into the local environment of the promoter atoms ( $\mathrm{Co}$ or $\mathrm{Ni})$ in the structure [14-16].

However, some key questions remained open because different atomistic models were still compatible with the experimental data. On the basis of total energy calculations, DFT calculations were thus helpful to discriminate between the proposed atomistic models. For a more detailed presentation of the recent progress made in that field, the reader could refer to two reviews devoted to DFT simulations applied to $\mathrm{Co}(\mathrm{Ni}) \mathrm{MoS}$ catalysts $[22,23]$. The earlier DFT simulations investigate the numerous possible locations for $\mathrm{Co}$ in the structure, including the effect of sulfur coverage at the edge [24]. They demonstrated that the most stable models are those where $\mathrm{Co}$ (or $\mathrm{Ni}$ ) substitutes $\mathrm{Mo}$ at the S- or M-edge. The optimized local Co-Mo and $\mathrm{Co}-\mathrm{S}$ distances for these two most stable configurations are fully compatible with the EXAFS analysis. Schweiger et al. put forward two distinct behaviors at the metallic-edge and sulfur-edge with respect to the Co or Ni promoter [25]. They found that Co is more stable in substitution at the Sedge than $\mathrm{Ni}$ due to a smaller edge energy at the S-edge. This preferential location of Co is also supported by other DFT simulations [26] and scanning tunnel microscopy (STM) experiments on gold supported CoMoS [27]. This latter cutting edge technique brought also numerous insights consistent with DFT approaches on the local structures of the active phases [28].

The fluid catalytic cracking (FCC) process produces gasoline mainly composed of aromatics, isoalkenes and alkylthiophenes, to be further hydrotreated in a specific process where selective HDS is achieved. It represents thus a technical challenge to prevent the loss of octane number of gasoline (resulting from olefins hydrogenation) while simultaneously removing sulfur from alkylthiophenes. From a scientific point of view, it is still an open question why the CoMoS active phase exhibits an improved HDS/HydO selectivity with respect to NiMoS, being often empirically described as "more hydrogenating". The HDS/HydO selectivity has been the subject of recent experimental works on model molecules for FCC gasoline or real feed [29-33]. In specific conditions, it seems possible to modulate the HDS/HydO selectivity of the NiMoS $[30,33]$ and CoMoS [34] active phases.

Many DFT works have performed adsorption energy calculations of sulfur organic molecules including thiophene and dibenzothiophene [23, 35-40] and nitrogen organic molecules [22, 41, 42]. The HDS mechanism of thiophene derivatives on $\mathrm{MoS}_{2}$ was also investigated in recent DFT studies [43, 44]. However, to our knowledge, no DFT work was devoted to the theoretical investigation of olefins adsorption on CoMoS and NiMoS model catalysts in sulfo-reductive conditions, before the recent work by Krebs et al. [45].

The goal of the present paper is thus to provide an overview of some achievements obtained through density functional theory (DFT) modeling of HDS catalysts. After a first section recalling briefly the methodological aspects, we focus on the $\mathrm{Co}(\mathrm{Ni}) \mathrm{MoS}$ active phases where various key scientific questions are addressed about the promoter location and content, together with the effects of morphology and reaction conditions. In the third section, we address the case study of HDS/HydO selectivity. Based on structure-activity relationships, we outline how DFT modeling helps to explore periodic trend in HDS/HydO selectivity. Combining DFT calculations of the adsorption energies with kinetic modeling leads to a new interpretation of volcano curves in the field of HDS/HydO selectivity.

\section{THEORETICAL METHODS}

The general approach which combines DFT calculations and the chemical potential of the gas phase was previously undertaken to study surface thermochemistry of GaAs [46, 47], c-BN [48] and $\alpha-\mathrm{Fe}_{2} \mathrm{O}_{3}$ [49]. An overview of first principles surface thermodynamics providing a rational way to investigate the local properties of active sites on various catalytic surfaces can be found in two recent reviews [50, 51]. This 
approach successfully applied to $\mathrm{MoS}_{2}$ and $\mathrm{Co}(\mathrm{Ni}) \mathrm{MoS}$ active phase was firstly reported in [24, 52]. Other studies have also used this systematic approach to investigate complex industrial catalytic systems such as the surfaces of $\gamma$-alumina support [53] and $\gamma$-alumina supported $\mathrm{MoS}_{2}$ catalyst [54, 55]. These examples illustrate how to bridge the gap between 0 K-DFT calculations and realistic model of catalysts in working conditions.

To determine by theoretical approaches the stable chemical species on the catalytic edge of $\mathrm{Co}(\mathrm{Ni}) \mathrm{MoS}$ in reaction conditions $\left(p_{i}, T\right)$ at thermodynamic equilibrium, one can minimize the edge energy given by the following general expression:

$$
\begin{gathered}
\sigma_{\text {edge }}\left(p_{i}, T, \theta_{i}\right)=\sigma_{\text {edge }}^{\text {vac }}+\sum_{i} \theta_{i}\left(E_{\text {ads }}^{i}+\Delta \mu_{i}\right) \\
\Delta \mu_{i}\left(T, p_{i}\right)=h_{i}^{0}-T s_{i}^{0}+R T \ln \left(\frac{p_{i}}{p^{0}}\right)-e_{i}
\end{gathered}
$$

$\sigma_{\text {edge }}$ is the edge energy of the $\mathrm{Co}(\mathrm{Ni}) \mathrm{Mo} \mathrm{S}$ - or M-edge in reaction conditions, $\sigma_{\text {edge }}^{v a c}$ is the edge energy of the reference $\mathrm{Co}(\mathrm{Ni}) \mathrm{Mo} \mathrm{S}$ - or M-edge (generally as cleaved in vacuum). $E_{a d s}^{i}$ is the adsorption energy of the reactant $i$, such as $\mathrm{H}_{2} \mathrm{~S}, \mathrm{H}_{2}$ or model reactants (methyl-thiophene and olefin) in the cases investigated so far. The most stable adsorption mode of the molecule $i$ (either dissociative or non-dissociative) is determined as a function of the surface coverage $\theta_{i}$ of the molecule. In the present case, $\Delta \mu_{i(i=S)}$ represents the chemical potential of $S$ in the gas phase: it depends on the partial pressures of $\mathrm{H}_{2} \mathrm{~S}$ and $\mathrm{H}_{2}$ and temperature according to (2). $h_{i}, s_{i}$ and $e_{i}$ are the enthalpy, entropy and internal energy of the $\mathrm{H}_{2} \mathrm{~S}$ and $\mathrm{H}_{2}$ gas phase molecules. The values of $\Delta \mu_{S}$ as a function of $p\left(\mathrm{H}_{2} \mathrm{~S}\right), p\left(\mathrm{H}_{2}\right)$ and $T$ ranges considered in this manuscript for the transition metal sulfides catalysts are explained elsewhere [54]. For sake of clarity, we indicate on the thermodynamic diagrams, the $\Delta \mu_{S}$ and $p\left(\mathrm{H}_{2} \mathrm{~S}\right) / p\left(\mathrm{H}_{2}\right)$ values for a given $T=525 \mathrm{~K}$ close to usual reaction conditions of selective HDS of FCC gasoline.

The energy values such as $\sigma_{e d g e}^{v a c}$, and $E_{a d s}^{i}$ are the outcome of simulations based on DFT within the generalized gradient approximation (GGA) [56]. To solve the Kohn-Sham equations [57, 58], results reported hereafter use the Vienna Ab initio Simulation Package (VASP) [59]. The ion-electron interactions are treated by the projected augmented wave (PAW) formalism [60]. For simulations of solid phases with delocalized electronic charges, it is efficient to employ a plane wave basis set to project the wavefunctions in a 3D-supercell representing the systems (bulk or slabs) with periodic boundary conditions. All detailed hypotheses of the calculations (such as electronic convergence criteria, energy cut-off, k-point mesh, relaxation conditions, etc.) can be found in papers cited herein.

\section{ATOMISTIC DESCRIPTION OF THE CO(NI)MOS ACTIVE PHASES}

\subsection{Case of the CoMoS Active Phase}

As mentioned in Introduction, DFT simulations has helped to bring numerous insights on the active phase atomic structure $[24,25,61,62]$, one interesting question remained open at this stage, about the precise control of the promoter content on the stability and morphology of the $\mathrm{Co}(\mathrm{Ni}) \mathrm{MoS}$ nanocrystallites. This question was recently addressed by Krebs $e t$ al. [63]. In what follows, we report the main result of this study.

The edge energy diagrams, as defined in the Methods section, are plotted in Figure 1 where the values are given for the M-edge and S-edge energy as a function of the reaction conditions $\left(\Delta \mu_{S}\right.$ and $\left.p\left(\mathrm{H}_{2} \mathrm{~S}\right) / p\left(\mathrm{H}_{2}\right)\right)$ for two promoter (Co or $\mathrm{Ni})$ edge contents $(50 \%$ and $100 \%)$. Numerous configurations for the S-adsorption and promoter distribution at the edges have been investigated: only the most relevant configurations and S-coverages are also reported in Figure 2.

The affinity of the Co promoter for the S-edge and for the M-edge can be compared by considering the energy diagram in Figure 1a. Different trends are revealed depending on the sulfo-reductive conditions. At high chemical potential of sulfur $\left(\Delta \mu_{S}>-0.6 \mathrm{eV}\right)$, Co exhibit a similar affinity for both edges. The edge energies for $100 \%$ Co are almost identical, which shows that a highly sulfiding regime (high $\left.p\left(\mathrm{H}_{2} \mathrm{~S}\right) / p\left(\mathrm{H}_{2}\right)\right)$ tends to stabilize the promoter on both edges. In contrast, the decrease of the partial pressure of $\mathrm{H}_{2} \mathrm{~S}$ or the increase of temperature corresponding to $\Delta \mu_{S}<-0.6 \mathrm{eV}$ enhances the affinity of Co for the S-edge with respect to the M-edge. In particular, for typical HDS conditions $\left(-1<\Delta \mu_{S}\right.$ $<-0.8 \mathrm{eV}$ ), the energy of the S-edge with $100 \%$ Co is about $0.20 \mathrm{eV}$ per edge metal atom lower than the M-edge. Such reaction conditions are thermodynamically favorable for Co to be located at the S-edge, in coherence with earlier results $[25,61]$.

In addition, a new feature is revealed: a partial promoter decoration of the M-edge (corresponding to $50 \% \mathrm{Co}$ ) reduces significantly its edge energy, close to the S-edge value. For the S-edge, the $50 \%$ Co content becomes energetically more favorable only for $\Delta \mu_{S}<-1.0 \mathrm{eV}$. This result will have significant consequences for the morphology and the reactivity of active sites at the edges of the CoMoS phase, as detailed in the following sections.

From a structural point of view, at $\Delta \mu_{S}>-0.6 \mathrm{eV}$ (i.e. high $\left.p\left(\mathrm{H}_{2} \mathrm{~S}\right) / p\left(\mathrm{H}_{2}\right)\right)$, the M-edge exhibits $100 \%$ Co stabilized with $50 \% \mathrm{~S}$ (Fig. 2a). For $\Delta \mu_{S}<-0.6 \mathrm{eV}$, the $50 \%$ Co partial occupation with the M-edge covered by $25 \% \mathrm{~S}$ is stable. It is interesting to note that the alternate configuration - Co-MoCo-Mo- (Fig. 2b) and the pairing configuration -Co-Co-MoMo- (Fig. 2c) are very close in energy. In both cases, the 

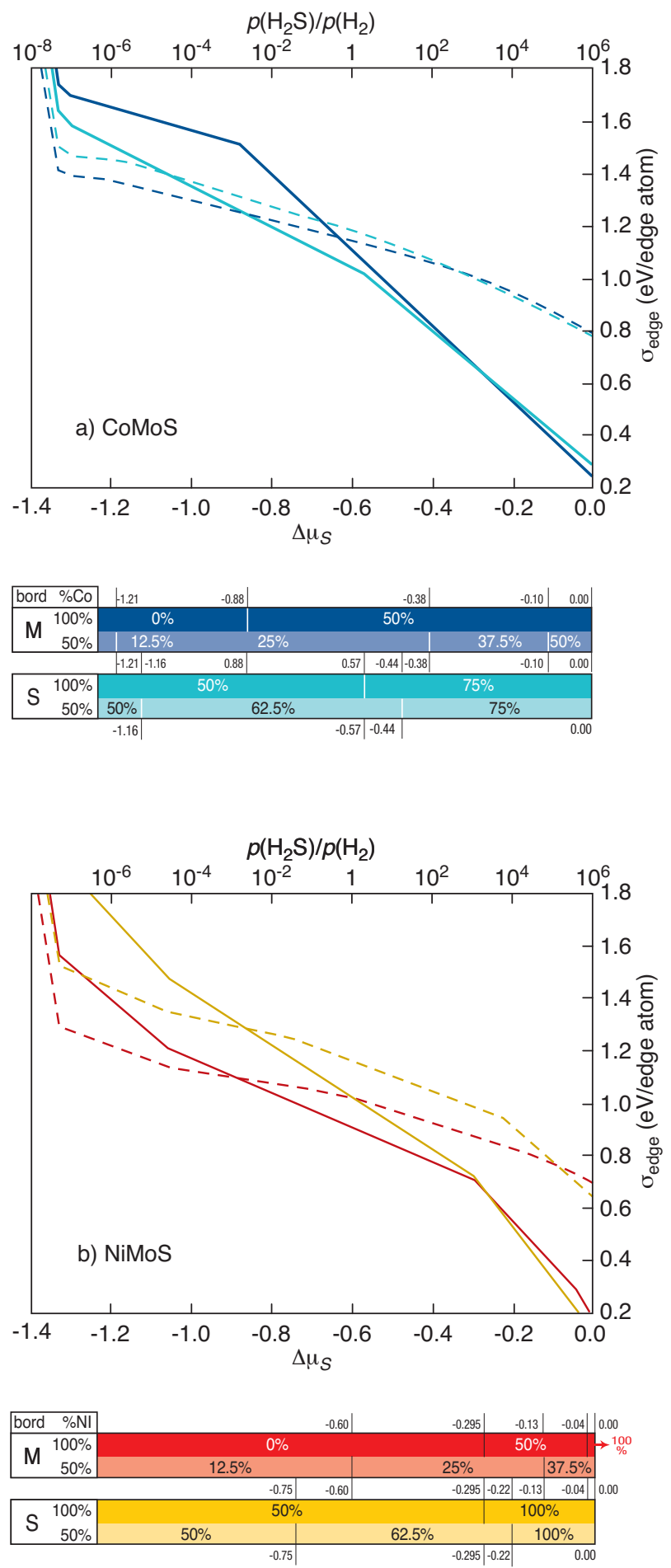

Figure 1

Edge energy diagrams as a function of $\Delta \mu_{S}$ and $p\left(\mathrm{H}_{2} \mathrm{~S}\right) / p\left(\mathrm{H}_{2}\right)$ (for $T=525 \mathrm{~K}$ ): a) Co-promoted M-edge (dark blue) and S-edge (light blue), b) Ni-promoted M-edge (red) and S-edge (yellow) for the two promoter edge contents: $50 \%$ (dashed line) and $100 \%$ (full line). The most stable S coverages for each promoter content and each edge are reported on the bar charts at the bottom of both diagrams. (Adapted from [63]).

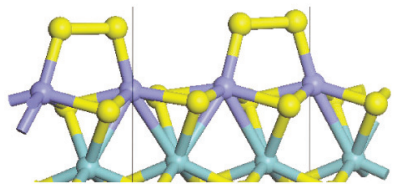

a)

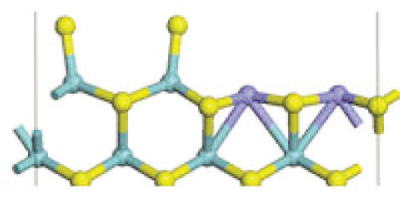

c)

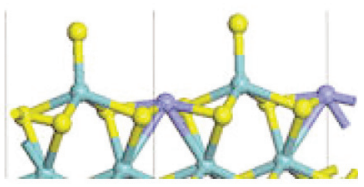

b)

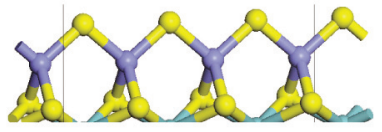

d)
Figure 2

Local edge structures after geometry optimization of the two CoMoS edges: a) M-edge with $100 \%$ Co and $50 \% \mathrm{~S}, \mathrm{~b}$ ) M-edge with $50 \%$ Co in an alternate position and $25 \% \mathrm{~S}, \mathrm{c}$ ) M-edge with $50 \%$ Co in a pairing configuration and $25 \% \mathrm{~S}$, d) S-edge with $100 \%$ Co and $50 \%$ S. Yellow balls: Sulfur, green balls: molybdenum, blue balls: cobalt. (Adapted from [63]).

M-edge structure exhibits mixed Co-Mo sites and the S-atom sits preferentially on top of the Mo atoms. The configuration of Co pairs is also compatible with the interpretation of magnetic susceptibility measurement by Okamoto proposing the existence of Co sulfide dinuclear Co species at the M-edge [64]. We also find that $\mathrm{S}$ bridging positions (not shown) are rather close in energy (only $0.04 \mathrm{eV}$ higher) which means that the mobility of S-atoms on the M-edge is high. For the S-edge, the most stable structure in HDS conditions, contains $100 \%$ Co and 50\% S (Fig. 2d), where Co atoms are in a tetrahedral environment confirming earlier DFT results [25, 61] and STM experiments [65]. At the lower limit of HDS conditions $\left(\Delta \mu_{S}<-1 \mathrm{eV}\right)$, the partial decoration of Co becomes favored with a sulfur coverage of about $62.5 \% \mathrm{~S}$. In all cases (including mixed Co-Mo sites), the optimized local Co-Mo distances are comprised between 2.74 and $2.84 \AA$ for the M-edge and are around $2.97 \AA$ for the S-edge, which remains compatible with EXAFS data [66, 67].

\subsection{Case of the NiMoS Active Phase}

A similar energy analysis for the NiMoS edges (Fig. $1 b$ ) reveals a different trend in the decoration of the mixed phase, especially in HDS conditions. At high chemical potential of sulfur $\left(\Delta \mu_{S}>-0.3 \mathrm{eV}\right)$, the energies of both edges are almost identical. As found for the CoMoS phase, Ni decorates $100 \%$ of the edge sites with similar affinity for M- and S-edges. In contrast, for $\Delta \mu_{S}<-0.3 \mathrm{eV}$ and especially in HDS conditions, the M-edge energy becomes lower than the one of the $\mathrm{S}$-edge. This trend is thus opposite to the CoMoS case. The $\mathrm{S}$-edge exhibits an energy higher by about $+0.2 \mathrm{eV}$ per edge 
metal atom, which implies that $\mathrm{Ni}$ is thermodynamically more stable on the M-edge. This result confirms previous DFT calculations [25]. In addition, the new feature is that the energies of the $100 \%$ and $50 \% \mathrm{Ni}$ edge contents are identical for $\Delta \mu_{S}=-0.9 \mathrm{eV}$ for both edges. As a consequence, the NiMoS phase nano-crystallites may exhibit either fully or partially decorated edges in HDS conditions. The partial decoration corresponds to the existence of mixed Ni-Mo edge sites, as described in the following paragraph.

The stable edge structures found for the NiMoS system are reported in Figure 3. Due to the stabilization of the $\mathrm{Ni}$ promoted M-edge, two competing structures are relevant in HDS conditions: the fully substituted M-edge with $0 \% \mathrm{~S}$ coverage (Fig. 3a) and the partially decorated M-edge with $12.5 \% \mathrm{~S}$ coverage (Fig. 3 b). In both cases, $\mathrm{Ni}$ is in a square planar environment. For $50 \% \mathrm{Ni}$ at the M-edge, the S-atom sits in a bridging position between two Mo-atoms. The S-Mo bond energy (significantly stronger than $\mathrm{S}-\mathrm{Ni}$ ) implies that the pairing configuration - Ni-Ni-Mo-Mo- is strongly stabilized (by $0.44 \mathrm{eV}$ per edge metal atom) versus the alternate configuration -Ni-Mo-Ni-Mo-, which was possible on the $\mathrm{CoMoS}$ system. This feature also distinguishes the NiMoS system from the CoMoS one. On the S-edge, at high chemical potential of sulfur, the stable edge with $100 \% \mathrm{Ni}$ is covered by $50 \% \mathrm{~S}$ (Fig. 3c). The local edge reconstruction leads to a square planar environment for the $\mathrm{Ni}$ atom, and $\mathrm{Ni}-\mathrm{Ni}$ pairing. For the $50 \% \mathrm{Ni}$ content, two competing configurations are possible. The first one (Fig. $3 d$ ) is the alternate configuration -Ni-Mo-Ni-Mo-, the second one is a pairing configuration -Ni-Ni-Mo-Mo- where the local structure of Ni is also square planar. In all cases, the optimized local Ni-Mo distances (between 2.75 and $2.87 \AA$ ) are compatible with

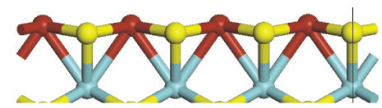

a)

c)

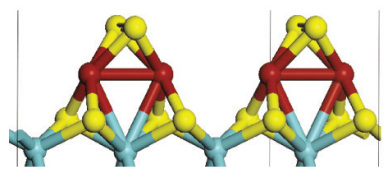

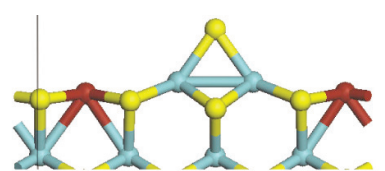

b)

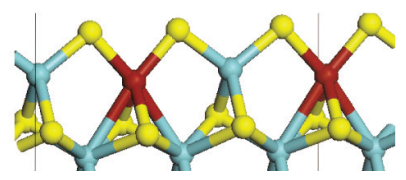

d)
Figure 3

Edge structures after geometry optimization of the two NiMoS edges: a) M-edge with $100 \% \mathrm{Ni}$ and $0 \% \mathrm{~S}$; b) M-edge with $50 \% \mathrm{Ni}$ in a paring configuration and $12.5 \% \mathrm{~S}$; c) S-edge with $100 \% \mathrm{Ni}$ and $50 \% \mathrm{~S}$; d) S-edge with $50 \% \mathrm{Ni}$ and $50 \%$ S. (Yellow balls: sulfur; green balls: molybdenum; brown balls: nickel), (adapted from [63]). earlier EXAFS characterization $[68,69]$. The square planar environment which is less stable for the Co promoter of $\mathrm{Ni}$ is thus a key structural feature of Ni promoter's environment. On both edges, the local structures reveal the existence of mixed Ni-Mo sites in HDS conditions.

\subsection{Nano-Crystallite Morphologies}

Using the calculated edge energies and the Gibbs-CurieWulff equations [70,71], the equilibrium morphologies are determined in the diagrams of Figures 4 and 5. The blue broken line is representative of the proportion of M-edge (\% Medge). This proportion varies with $\Delta \mu_{S}$, meaning that the equilibrium morphology depends on the reaction conditions or sulfidation conditions. The various domains of promoter edge content and sulfur coverage are also reported in Figure 4 . For a given reaction condition (fixed by $\Delta \mu_{S}$ ), the equilibrium shape and the composition of each edge can be deduced from the diagram.

If we first consider a CoMoS nano-crystallite close to HDS reaction conditions $\left(-1.0 \leq \Delta \mu_{S} \leq-0.8 \mathrm{eV}\right.$ represented by the gray region in Figure 4, the proportion of M-edge is close to 50\% (hexagonal shape). The S-edge contains 100\% Co covered by $50 \% \mathrm{~S}$, whereas the M-edge exhibits $50 \% \mathrm{Co}$ covered by $25 \% \mathrm{~S}$ competing with the non promoted $\mathrm{M}$ edge. Assuming a typical average crystallite size of $35 \AA$, the two corresponding models for the $\mathrm{CoMoS}$ nano-crystallites are drawn in the insets a), b) and c) of Figure 4.

On inset c) corresponding to the high $p\left(\mathrm{H}_{2} \mathrm{~S}\right) / p\left(\mathrm{H}_{2}\right)$, the $\mathrm{Co} / \mathrm{Mo}$ ratio is 0.49 . On inset $\mathrm{b}$ ) corresponding to the intermediate $\Delta \mu_{S}$, the Co/Mo ratio is 0.29 which is very close to the optimal ratio required for catalytic activity [72, 73]. In this case, it can be noticed that the number of mixed CoMo sites per crystallite is equal to 9 (including M-edge and corner sites). In slightly more reductive reaction conditions (inset a), the complete loss of $\mathrm{Co}$ is obtained from the Medge. In this case, the particle exhibits a $\mathrm{Co} / \mathrm{Mo}$ ratio of 0.20 is lower and the number of mixed sites is equal to 6 (corner sites only). It is interesting to notice that the DFT calculated morphology remains compatible with the geometrical model earlier proposed by Kasztelan et al. [7]. Furthermore, due to the fact that the active catalyst exhibits $\mathrm{Co} / \mathrm{Mo}$ values close to 0.30 , the role of mixed Co-Mo sites at the edges or corners of the crystallites appear to be crucial as also discussed in [72].

For the NiMoS active phase, the variation of the morpho$\operatorname{logy}$ as a function of reaction conditions is more pronounced as indicated by the diagram of Figure 5. The morphology at high $p\left(\mathrm{H}_{2} \mathrm{~S}\right) / p\left(\mathrm{H}_{2}\right)$ (inset c) exhibits the predominant fully promoted S-edge (close to $70 \%$ ). In HDS conditions $\left(-1.0 \mathrm{eV} \leq \Delta \mu_{S} \leq-0.8 \mathrm{eV}\right)$, the morphology is a deformed hexagon exposing a M-edge proportion of $65 \%$. However, the situation is more complex, because for chemical potential 


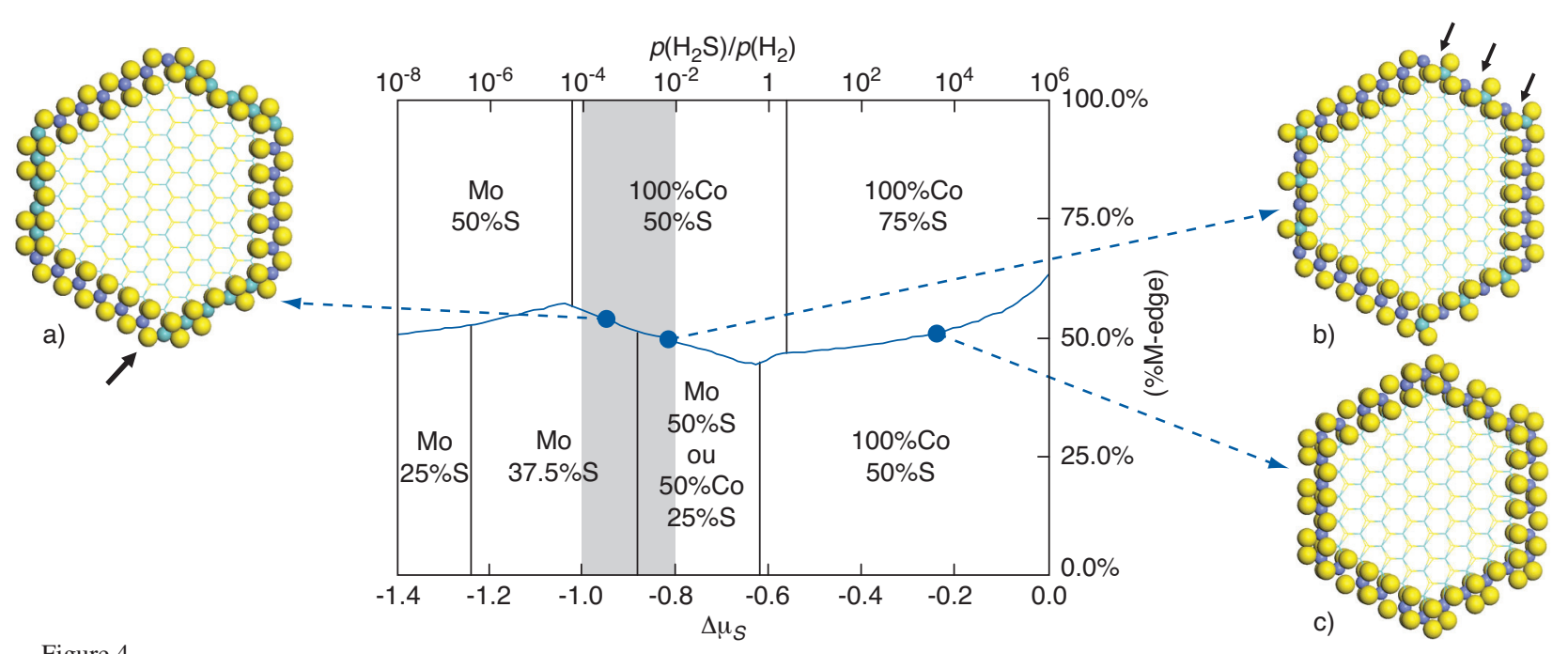

Figure 4

Morphology diagrams for the CoMoS nano-crystallites as a function of $\Delta u_{S}$ and $p\left(\mathrm{H}_{2} \mathrm{~S}\right) / p\left(\mathrm{H}_{2}\right)$ (for $T=525 \mathrm{~K}$ ). The percentage of M-edge is indicated by the blue broken line. The S-edge compositions are reported above the blue line, and the M-edge compositions are below this line. The gray region visualizes the range of usual HDS conditions. (Adapted from [63]). The insets give the ball and stick representations of three possible CoMoS morphologies, with mixed sites indicated by arrows (same color legend as Fig. 2).
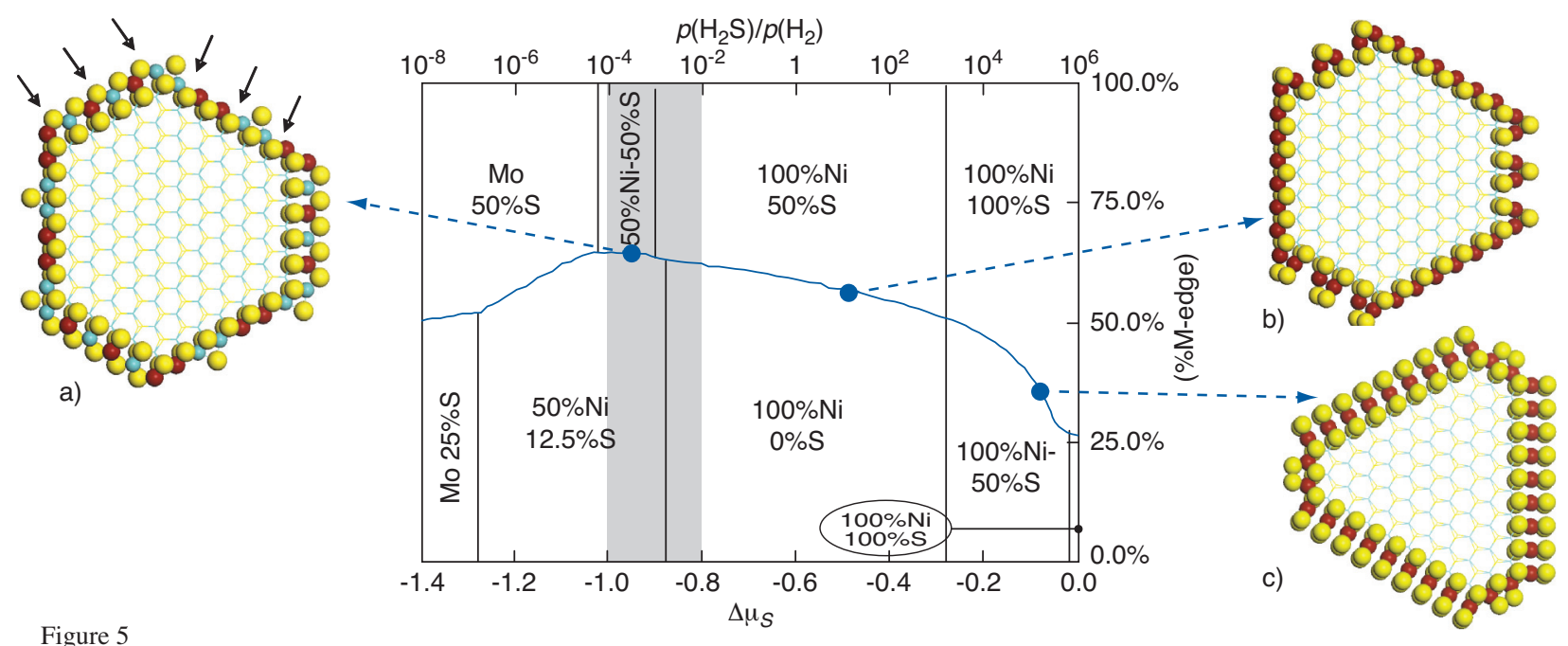

Figure 5

Morphology diagrams for the NiMoS nano-crystallites as a function of $\Delta \mu_{S}$ and $p\left(\mathrm{H}_{2} \mathrm{~S}\right) / p\left(\mathrm{H}_{2}\right)$ (for $T=525 \mathrm{~K}$ ). The percentage of M-edge is indicated by the blue broken line. The S-edge compositions are reported above the blue line, and the M-edge compositions are below this line. The gray region visualizes the range of usual HDS conditions. (Adapted from [63]). The insets give a ball and stick representation of three possible NiMoS morphologies (same color legend as Fig. 3).

value corresponding to HDS, four edge configurations compete in the gray region of Figure 5: these four configurations result from a combination of $100 \% \mathrm{Ni}$ (inset b) and $50 \% \mathrm{Ni}$ (inset a) either at S-edge or at M-edge. This implies that four local edge structures can be considered for the equilibrium morphology: for sake of clarity, only two of them are represented in Figure 5, even if all combinations of each type of edge are possible. The model maximizing the number of mixed edge Ni-Mo sites (18) and minimizing the Ni/Mo ratio
(0.17) should be obtained at lower $p\left(\mathrm{H}_{2} \mathrm{~S}\right) / p\left(\mathrm{H}_{2}\right)$. In contrast, the model, corresponding to higher $p\left(\mathrm{H}_{2} \mathrm{~S}\right) / p\left(\mathrm{H}_{2}\right)$, maximizes the promoter content $(\mathrm{Ni} / \mathrm{Mo}$ ratio of 0.40$)$ and minimizes the number of mixed sites. According to the usual $\mathrm{Ni} / \mathrm{Mo}$ ratio (smaller than 0.40) observed by XPS and required for best HDS activities [8,9], the working crystallites must combine edge structures allowing the presence of mixed Ni-Mo edge sites. This point will be analyzed in details in the paper by $\mathrm{K}$. Marchand et al. published in the present volume [82]. 
Recent STM experiments have also revealed the presence of mixed Ni-Mo sites on the edges of NiMoS nano-crystallites [28], whereas such a situation has not been observed for CoMoS [65]. There is thus a striking agreement between the DFT calculations and STM experiments, which both reveal that Co prefers to be located at the S-edge, whereas Ni is present on both S- and M-edge. Combined IR and DFT studies of $\mathrm{CO}$ adsorption on $\mathrm{Co}(\mathrm{Ni}) \mathrm{Mo}$ sulfide catalysts have also suggested that low wavenumbers (below $2060 \mathrm{~cm}^{-1}$ ) are the signature of Mo centers adjacent to promoter atoms, confirming partial edge decoration [74].

In addition, for $\Delta \mu_{S}<-1.0 \mathrm{eV}$, the reductive environment or the high reaction temperature becomes a destabilizing factor for Co at the M-edge and is at the origin of the full segregation of Co to this edge. Thus, a loss of the mixed active sites located on the M-edge is suspected if the reaction conditions become too severe. In contrast, the complete loss of $\mathrm{Ni}$ from the M-edge would appear at $\Delta \mu_{S}<-1.3 \mathrm{eV}$, which means that pure Ni sites or mixed Ni-Mo sites remain stable at this edge on a large range of sulfo-reductive conditions. On the S-edge, the full segregation of the promoter from the Sedge occurs for $\Delta \mu_{S}<-1.05 \mathrm{eV}$, i.e. at the frontier of the HDS domain for both CoMoS and NiMoS. This means that the destabilization of the mixed S-edge sites phase may occur if too strongly reductive conditions are explored. Indeed, earlier Mössbauer spectroscopy characterization by Breysse $e t$ $a l$. revealed that the mixed CoMoS phase undergoes structural modification after reaction under high hydrogen pressure and high temperature [12]. This observation finds its explanation in the thermodynamic segregation quantified by the larger increase of the edge energies of the CoMoS with respect to the non promoted system in such conditions.

\section{APPLICATION TO HDS/HYDO SELECTIVITY}

\subsection{Introduction}

One objective of DFT investigations is the rational understanding of industrial $\mathrm{Co}(\mathrm{Ni}) \mathrm{MoS}$ active phases in order to propose new concepts helping for the improvement of the resulting catalytic activities. DFT calculations of relevant energy descriptors are well suited for providing a predictive approach. For instance, the binding energy of atomic nitrogen on transition metal surfaces was found as a relevant chemical descriptor for the catalytic activity in ammonia synthesis on metals through volcano curve relationships [75].

For HDT reactions, the sulfur-metal bond energy is a relevant intrinsic descriptor of the active phase to be correlated with activities. More precisely, it was shown that the sulfur-metal bond energy, $E_{M S}$, as defined as a partitioning of the cohesive energies among all types of bonds present in the TMS simulation cell [76-78], correlates well with the HDS activity via a volcano master curve. The optimal catalysts are found for intermediate value of $E_{M S}$ in agreement with the Sabatier principle [79]. In what follows, we focus on a new case study of volcano curves applied to the HDS/HydO selectivity as recently highlighted by combined experimental, kinetic and DFT approaches [29, 30, 45].

\subsection{Kinetic Model of HDS/HydO Selectivity}

The better understanding of the selective hydrodesulfurization of FCC gasoline represents an interesting scientific question addressed to DFT calculations. It is particularly challenging to remove sulfur atoms from alkylthiophene in a reductive environment without hydrogenation of olefins (in order to keep the high octane number). According to the composition of the feed to be treated, it was found that a relevant model molecule for the HDS reaction is 2-methylthiophene (called 2MT), and a relevant olefin for HydO is 2,3-dimethylbut-1ene (called 23DMB1N) at equilibrium with 2,3-dimethylbut2-ene [31,32].

According to previous kinetic studies [29, 30] using Langmuir-Hinshelwood formalism, it has been shown that the turnover frequencies (TOF) of HDS of 2MT and HydO of 23DMB1N also follow volcano curve relationships when expressed as a function of the sulfur-metal bond energy, $E_{M S}$. For obtaining such volcano trends, it was required to assume linear relationships between adsorption energies of both reactants and the $E_{M S}$ descriptor as well as Brønsted-EvansPolanyi relationships between activation energies of the HDS and $\mathrm{HydO}$ rate determining steps and the $E_{M S}$ descriptor. For both HydO and HDS activities, the optimal catalysts were found close to $\mathrm{Rh}_{2} \mathrm{~S}_{3}$, NiMoS and CoMoS (i.e. at intermediate values of $E_{M S}$ ). The volcano shape still holds when $\mathrm{HydO}$ and HDS are considered as competing reactions for the same active sites. Moreover, the kinetic model also shows that the HDS/HydO selectivity also follows a volcano curve relationship (Fig. 6). The key difference is observed on the position of the volcano maximum of $\mathrm{HDS} / \mathrm{HydO}$ selectivity is shifted to higher $E_{M S}$ values than for the HDS or HydO reactions.

Considering the first hydrogenation step as the kinetic determining step [29, 30], the fitted activation enthalpies of the rate determining step for HydO of 23DMB1N and HDS of $2 \mathrm{MT}$ are $\Delta G^{\neq}=+59 \mathrm{~kJ} / \mathrm{mol}$ and $\Delta G^{\neq}(\mathrm{HDS})=+109 \mathrm{~kJ} / \mathrm{mol}$ respectively. The selectivity ratio of HDS and HydO TOFs can be expressed as a function of the $\theta_{i}$ coverages of 2MT, 23DMB1N and $-\mathrm{SH}$ species involved in the rate determining step:

$$
\frac{r(\mathrm{HDS})}{r(\mathrm{HydO})}=\frac{k_{H D S} \theta_{M T} \theta_{S H}}{k_{H y d O} \theta_{23 D M B 1 N} \theta_{S H}}=e^{-\frac{\delta \Delta G^{*}+\delta \Delta G_{\text {edgee }}}{R T}}
$$

where $\delta \Delta G^{\ddagger}=\Delta G^{\ddagger}(\mathrm{HDS})-\Delta G^{\ddagger}(\mathrm{HydO}) \approx+50 \mathrm{~kJ} / \mathrm{mol}$, according to [30] and:

$$
\delta \Delta G_{\text {edge }}=\Delta G_{\text {edge }}(2 \mathrm{MT})-\Delta G_{\text {edge }}(23 \mathrm{DMB} 1 \mathrm{~N})
$$




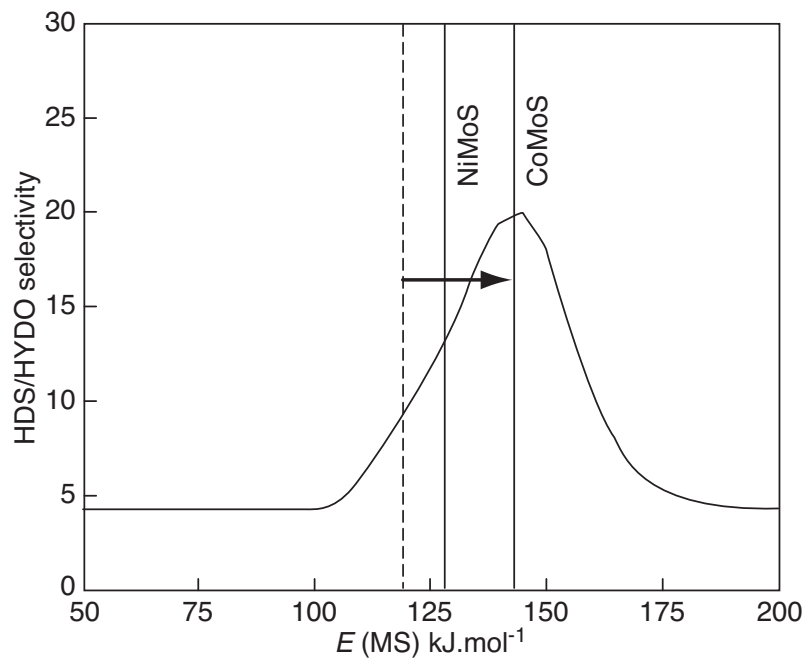

Figure 6

Volcano curve of HDS/HydO selectivity obtained from the kinetic model. The dashed line recalls the volcano curves' maximum obtained for HDS of 2MT or HydO of 23DMB1N for reaction temperature of $525 \mathrm{~K}$. (Adapted from [30]).

$\delta \Delta G_{\text {edge }}$ quantifies the adsorption selectivity (adsorption competition), by evaluating the difference of the Gibbs free energies of the catalytic edge (or catalytic surface) in presence of the two adsorbed molecules (2MT and 23DMB1N). A negative value of $\delta \Delta G_{\text {edge }}$ indicates a selective adsorption of $2 \mathrm{MT}$ versus $23 \mathrm{DMB} 1 \mathrm{~N}$, i.e. a stronger affinity of $2 \mathrm{MT}$ for the edge. $\delta \Delta G_{\text {edge }}$ is directly correlated to $\sigma_{\text {edge }}$ defined by Equation (1):

$\delta \Delta G_{\text {edge }}=\frac{1}{\theta_{M T}} \sigma_{\text {edge }}(2 \mathrm{MT})-\frac{1}{\theta_{23 \mathrm{DMB} 1 \mathrm{~N}}} \sigma_{\text {edge }}(23 \mathrm{DMB} 1 \mathrm{~N})$

In the case of $\mathrm{Co}(\mathrm{Ni}) \mathrm{MoS}$, the supercell used for the simulation implies that $\theta_{M T}=\theta_{23 D M B 1 N}=1 / 4$ and thus $\delta \Delta G_{\text {edge }}=$ $4 \Delta \sigma_{\text {edge }}$.

According to Equation (1), it can be stressed that the variation of $\delta \Delta G_{\text {edge }}$ is mainly governed by the adsorption energy difference of the two reactants, $E_{a d s}(2 \mathrm{MT})-E_{a d s}$ (23DMB1N). In addition, the chemical potential $\Delta \mu_{S}$ may also impact the $\delta \Delta G_{\text {edge }}$ index, if different sulfur coverages are stabilized in presence of the adsorbed molecules. Finally, the relative partial pressures of 2MT and 23DMB1N modify the relative coverages of the two reactants and as a result the $\delta \Delta G_{\text {edge }}$ index.

Considering that the kinetic term is generally in favor of the HydO reaction $\left(\delta \Delta G^{\neq}=+50 \mathrm{~kJ} / \mathrm{mol}\right)$, the $\mathrm{HDS} / \mathrm{HydO}$ selectivity becomes greater than 1 (according to Equation (3)) only if $\delta \Delta G^{\neq}$is counterbalanced by the thermodynamic term, $\delta \Delta G_{\text {edge }}$. For that, $\delta \Delta G_{\text {edge }}$ must be inferior to the critical value of $\sim-50 \mathrm{~kJ} / \mathrm{mol}$.

\subsection{DFT Calculations of Adsorption on Co(Ni)MoS}

Thanks to the precise determination of active sites on $\mathrm{Co}(\mathrm{Ni}) \mathrm{MoS}$ systems (see Section 2.1), it is possible to precisely evaluate $\delta \Delta G_{\text {edge }}$. We have recently undertaken an exhaustive investigation of the adsorption configurations and energies for the 2MT and 23DMB1N molecules on the different types of $\mathrm{Co}(\mathrm{Ni}) \mathrm{MoS}$ edges [45]. In what follows, we report the most relevant adsorption results helping for the kinetic interpretation of HDS/HydO selectivity. For instance, Figure 7 shows that the adsorption energies of 2MT on the CoMo S-edge is generally favoured with respect to the 23DMB1N molecule. This is mainly due to the interaction of the S-atom of 2MT on this edge, whereas the $\pi$ interaction of the $\mathrm{C}=\mathrm{C}$ bond of the olefin is less favorable. An electronic analysis of the electron localization function basins formed between the molecules and the active sites has permitted to furnish an explanation of the trend in adsorption energies for the two reactants [80].

According to Equations (1) and (5), the adsorption energy values have been used to evaluate $\Delta \sigma_{\text {edge }}$ in the case of $\mathrm{Co}(\mathrm{Ni}) \mathrm{MoS}$ catalyst. The diagrams of Figure 8 represent the evolution of $\Delta \sigma_{\text {edge }}$ as a function of the partial pressure of $\mathrm{H}_{2} \mathrm{~S} / \mathrm{H}_{2}$ at a fixed temperature $(525 \mathrm{~K})$ close to the usual reaction conditions. It appears that for the S-edge of CoMoS, the $\Delta \sigma_{\text {edge }}$ value remains almost constant and close to -0.22 $\mathrm{eV}$ per edge atom, i.e. $\delta \Delta G_{\text {edge }}=-85 \mathrm{~kJ}$ per mole of reactant (being given 1 reactant per 4 edge atoms in the simulation cell). This means that $\delta \Delta G_{\text {edge }}$ largely counterbalances the $\delta \Delta G^{\neq}$value $(+50 \mathrm{~kJ} / \mathrm{mol})$. The resulting selectivity of $\mathrm{CoMoS}$ is so expected to be high as observed experimentally [81]. For NiMoS, the $\Delta \sigma_{\text {edge }}$ values are generally less in favor of the 2MT molecule: between -0.09 and $-0.03 \mathrm{eV}$ per edge atom, i.e. $\delta \Delta G_{\text {edge }}-34.7$ and $-11.6 \mathrm{~kJ} / \mathrm{mol}$ (particularly in the case of the fully promoted edge as shown in Fig. 8b). This
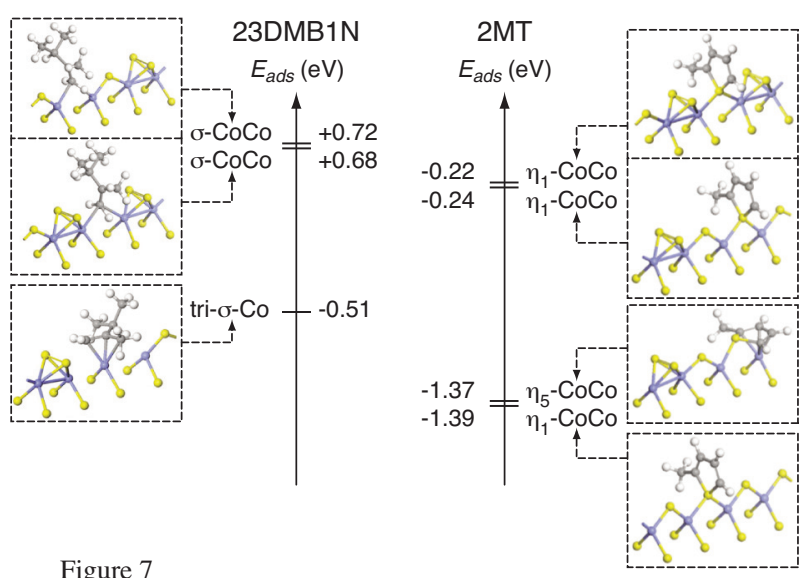

Figure 7

Adsorption configurations and energies (in $\mathrm{eV}$ ) of $2 \mathrm{MT}$ and 23DMB1N on the S-edge of the CoMoS catalyst. 

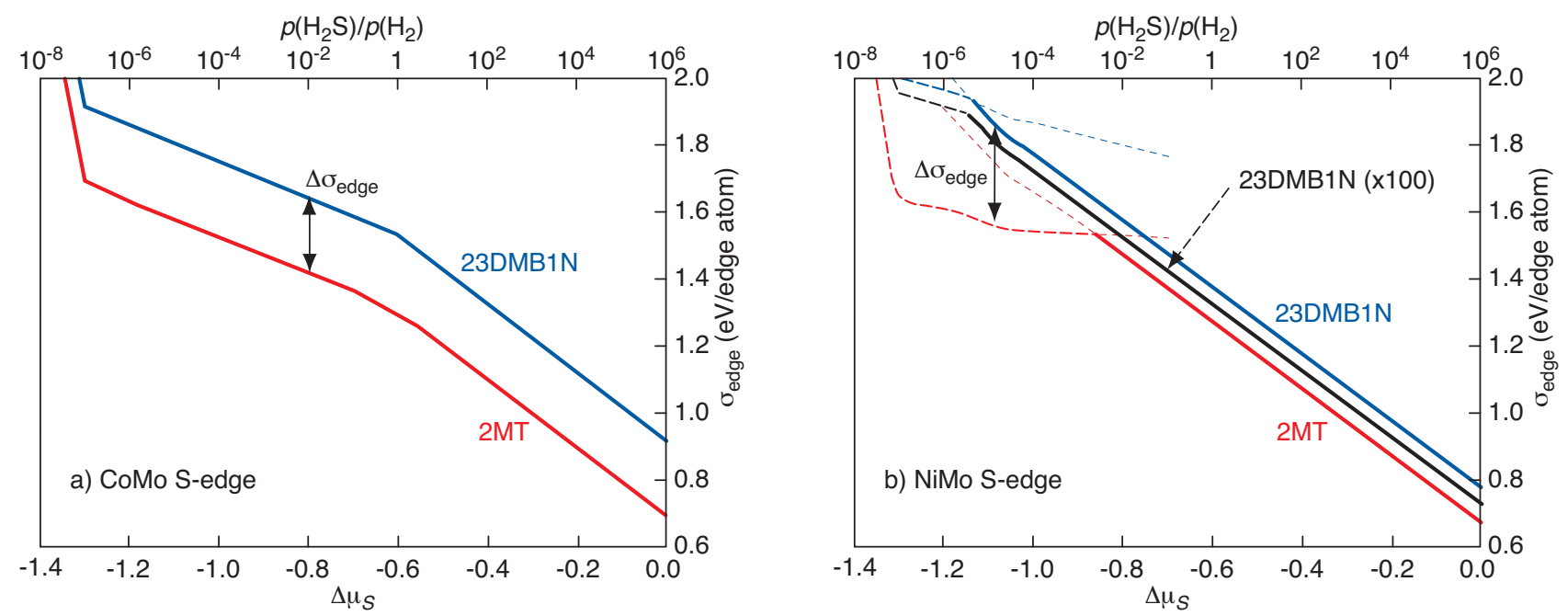

Figure 8

Edge energy diagram of molecules adsorbed on a) CoMoS S-edge with full Co decoration and b) on the NiMoS S-edge as a function of $\Delta u_{S}$. (full line: full promoter decoration at the edge, dashed line: partial promoter decoration, black line: the partial pressure of 23DMB1N is multiplied by 100). The $p_{\mathrm{H}_{2} \mathrm{~S}} / p_{\mathrm{H}_{2}}$ axis is determined for $T=525 \mathrm{~K}$.

implies that the $\delta \Delta G_{\text {edge }}$ value does not counterbalance the kinetic term. However, when reducing the $\mathrm{Ni}$ content at the edge (dashed lines in Fig. 8), the $\delta \Delta G_{\text {edge }}$ value becomes significantly more favorable $(-62$ and $-139 \mathrm{~kJ} / \mathrm{mol}$, i.e. $\Delta \mathrm{\sigma}_{\text {edge }}=-0.16$ and $-0.36 \mathrm{eV}$ ) and counterbalances the kinetic term. This implies that the NiMoS system may become as selective as CoMoS, which could explain recent experimental results [30]. Furthermore, as also shown by the black line in Figure $8 \mathrm{~b}$, the selectivity index depends on the relative partial pressures of the reactants. An increase of the partial pressure of the olefin (by a factor of 100) decrease the selectivity index by a factor of 2 . However, the selectivity seems to be less sensitive to this parameter than the nature and content of promoter at the edges.

It can be simultaneously shown, that the adsorption energies calculated by DFT are consistent with the fitted kinetic adsorption parameters proposed in [30]. This interpretation remains also consistent with the volcano curve of the HDS/HydO selectivity (Fig. 6) showing that the improvement of a NiMoS catalyst should be possible only if one can increase its intrinsic $E_{M S}$. The formation of mixed Ni-Mo sites at the edges of the crystallite must be enhanced, which is equivalent to an increase of the S-M bond energy induced by the presence of Mo edge atom.

\subsection{Extrapolation to Tin Doped Systems}

At this stage, it is also interesting to attempt to extrapolate our concept to the case of another potential promoter for the active phase, such as Tin atoms. The Sn deposition on
CoMoS active phase by surface organometallic chemistry was recently investigated by Choi et al. [34]. While Mössbauer spectroscopy show that Sn may be located also on the CoMoS phase, it was found that the effect of $\mathrm{Sn}$ is to decrease the HDS/HydO selectivity by a stronger inhibition of HDS activity than the HydO activity. The HydO activity was measured by using the transformation of the 23DMB2N model molecule, after being isomerized into 23DMB1N, whereas HDS was measured on 3-methylthiophene (3MT). Even if the 2MT (used in previous sections) and 3MT molecules differ from the position of the methyl group, it can be argued that the observed inhibiting effect of Sn on HDS would be greater on 2MT due to its larger steric hindrance.

Assuming in our DFT model that Sn atoms are susceptible to be present either at the M-edges and S-edges of the active phase nano-crystallites, we calculate with the same methodology, the adsorption energies of 2MT and 23DMB1N and the corresponding $\delta \Delta G_{\text {edge }}$ values. On the M- and S-edge fully substituted by $\mathrm{Sn}$, the adsorption energies are weak or even endothermic in the two cases, as illustrated in Figure 9. Such values correspond to physisorbed states, which explains the inhibiting effect of Sn atoms observed on both HDS and HydO activities.

Furthermore, according to these adsorption energies, we deduced that the $\delta \Delta G_{\text {edge }}$ values are -11 and $+26 \mathrm{~kJ} / \mathrm{mol}$ of reactant for the M-edge and S-edge respectively. As a consequence, such $\delta \Delta G_{\text {edge }}$ values, which cannot counterbalance $\delta \Delta G^{\ddagger}$, confirm that the Sn addition to $\mathrm{Co}(\mathrm{Ni}) \mathrm{MoS}$ active phase cannot improve the HDS/HydO selectivity with respect to CoMoS or NiMoS active phase. As a consequence, 


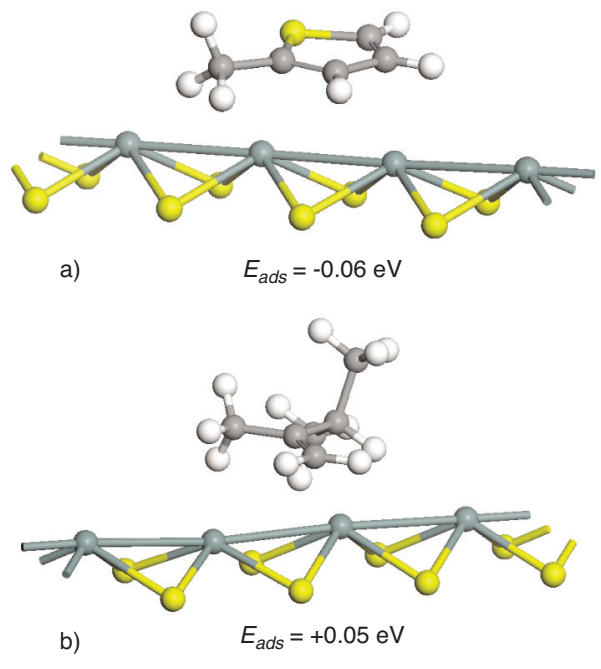

Figure 9

Adsorption configurations of a) $2 \mathrm{MT}$ and b) 23DMB1N on the M-edge fully promoted by $\mathrm{Sn}$. The adsorption energies, $E_{\text {ads }}$, are expressed in $\mathrm{eV}$. Yellow balls: Sulfur; gray balls: tin.

it seems possible to generalize the DFT concept established for the CoMoS and NiMoS to new potential promoter element $(\mathrm{X})$, under the assumption that a mixed $\mathrm{XMoS}$ phase is formed.

\section{CONCLUSIONS}

The overview presented in this paper has illustrated how DFT simulation helped to bring new atomic-scale insights on the active phase of HDS catalysts. The sulfo-reductive conditions (partial pressure of $\mathrm{H}_{2} \mathrm{~S} / \mathrm{H}_{2}$ and temperature) appear as a key parameter for controlling the morphology of the active phase and thus the type of exposed active sites. If the chemical potential of sulfur is low (i.e. at highly reductive environment or high $T$ reached in certain HDT conditions), the CoMoS phase may segregate into $\mathrm{MoS}_{2}$ and metallic Co, leading to a loss of the mixed phase and catalytic deactivation. In contrast, for high partial pressure of $\mathrm{H}_{2} \mathrm{~S}$, the DFT results show that the promoter is stabilized on both edges. This result implies that controlling the sulfo-reductive environment at the activation step of the catalyst or during operating conditions may be crucial to tune the promoter content at the edges.

Another striking finding revealed that Ni exhibits a higher affinity for the M-edge than for the S-edge, whereas it is the reverse for Co. A subtle but relevant difference in the local structure is thus revealed between CoMoS and NiMoS.

This rigorous active site description has provided new insights for the interpretation of the different catalytic behaviors of the CoMoS and NiMoS phases, particularly in the case of HDS/HydO selectivity. Moreover, the selective adsorption of reactants is suggested as a key parameter controlling the $\mathrm{HDS} / \mathrm{HydO}$ selectivity in $\mathrm{Co}(\mathrm{Ni}) \mathrm{MoS}$ phase. The S-edge of $\mathrm{Co}(\mathrm{Ni}) \mathrm{MoS}$ has been found to be more selective than the M-edge. Whereas the Co content on the edges has been found to hardly influence the adsorption selectivity, the $\mathrm{Ni}$ edge content is a key parameter for optimizing the HDS/HydO selectivity. Combining DFT calculations with kinetic modelling, it has been possible to give a consistent interpretation of catalytic selectivity on the basis of volcano curves and the DFT calculated selectivity index $\delta \Delta G_{\text {edge }}$.

\section{REFERENCES}

1 Euzen P., Raybaud P., Krokidis X., Toulhoat H., Loarer J.-L. Le, Jolivet J.-P., Froidefond C. (2002) Handbook of Porous Solids, Schüth F., Sing K.S.W., Weitkamp J. (Eds.), Wiley-VCH Verlag $\mathrm{GmbH}$, Weinheim, Vol. 3, p. 1591.

2 Topsøe H., Clausen B.S., Massoth F.E. (1996) Hydrotreating Catalysis - Science and Technology, Anderson J.R., Boudart M. (Eds.), Springer-Verlag, Berlin/Heidelberg, Vol. 11.

3 Prins R. (1997) Handbook of Heterogeneous Catalysis, Ertl G., Knözinger H., Weitkamp J. (Eds.), Wiley-VHC Verlagsgesellschaft, Weinheim, Vol.4, p. 1908.

4 Delannay F. (1985) High resolution electron microscopy of hydrodesulfurization catalysts: A review, Appl. Catal. 16, 135.

5 Payen E., Kasztelan S., Houssenbay S., Szymansky R., Grimblot J. (1989) Genesis and characterization by laser Raman spectroscopy and high-resolution electron microscopy of supported molybdenum disulfide crystallites, J. Phys. Chem.93, 6501 .

6 Alstrup I., Chorkendorff I., Candia R., Clausen B.S., Topsoe H. (1982) A combined X-Ray photoelectron and Mössbauer emission spectroscopy study of the state of cobalt in sulfided, supported, and unsupported Co-Mo catalysts, J. Catal.77, 397.

7 Kasztelan S., Grimblot J., Bonnelle J.P., Payen E., Toulhoat H., Jacquin Y. (1983) Preparation of Co-Mo- $\gamma-\mathrm{Al}_{2} \mathrm{O}_{3}$ and Ni-Mo- $\gamma-$ $\mathrm{Al}_{2} \mathrm{O}_{3}$ catalysts by $\mathrm{pH}$ regulation of molybdenum solution. characterization of supported species and hydrogenation activities, Appl. Catal. 7, 91.

8 Garreau F.B., Toulhoat H., Kasztelan S., Paulus R. (1986) Lowtemperature synthesis of mixed NiMo sulfides: structural, textural and catalytic properties, Polyhedron 5,211.

9 Houssenbay S., Kasztelan S., Toulhoat H., Bonnelle J.P., Grimblot J. (1989) Nature of the different nickel species in sulfided bulk and alumina-supported nickel-molybdenum hydrotreating catalysts, J. Phys. Chem. 93, 7176.

10 Wivel C., Candia R., Clausen B.S., Mørup S., Topsøe H. (1981) On the catalytic significance of a $\mathrm{Co}-\mathrm{Mo}-\mathrm{S}$ phase in Co$\mathrm{Mo} / \mathrm{Al}_{2} \mathrm{O}_{3}$ hydrodesulfurization catalysts: Combined in situ Mössbauer emission spectroscopy and activity studies, J. Catal. $\mathbf{6 8}, 453$.

11 Breysse M., Frety R., Benaïchouba B., Bussière P. (1983) Radiochem. Radioanal. Lett. 59, 265.

12 Breysse M., Frety R., Vrinat M. (1984) Unsupported cobalt molybdenum sulfide catalysts Part II: Characterization and evolution of physicochemical properties during catalytic reaction, Appl. Catal. 12, 165.

13 Payen E., Kasztelan S., Grimblot J. (1988) In situ Laser Raman Spectroscopy of the sulphiding of $\mathrm{WO}_{3}\left(\mathrm{MoO}_{3}\right) / \gamma-\mathrm{Al}_{2} \mathrm{O}_{3}$ catalysts, J. Mol. Struct. 174, 71.

14 Clausen B.S., Topsøe H., Candia R., Villadsen J., Lengeler B., Als-Nielsen J., Christensen F. (1981) Extended x-ray absorption fine structure study of the cobalt-molybdenum hydrodesulfurization catalysts, J. Phys. Chem. 85, 3868 . 
15 Clausen B.S., Topsøe H. (1989) In-situ studies of catalysts by XAFS and Mössbauer spectroscopy, Hyperfine Interact. 47, 203.

16 Bouwens S.M.A.M., Koningsberger D.C., de Beer V.H.J., Louwers S.P.A., Prins R. (1990) EXAFS study of the local structure of $\mathrm{Ni}$ in $\mathrm{Ni}-\mathrm{MoS}_{2} / \mathrm{C}$ hydrodesulfurization catalysts, Catal. Lett. 5, 273.

17 Calais C., Matsubayashi N., Geantet C., Yoshimura Y., Shimada H., Nishijima A., Lacroix M., Breysse M. (1998) Crystallite Size Determination of Highly Dispersed Unsupported $\mathrm{MoS}_{2}$ Catalysts, J. Catal. 174, 130.

18 Shido T., Prins R. (1998) Why EXAFS Underestimated the Size of Small Supported $\mathrm{MoS}_{2}$ Particles, J. Phys. Chem. B. 102, 8426.

19 Topsøe N.-Y., Topsøe H. (1983) Characterization of the structures and active sites in sulfided $\mathrm{Co}-\mathrm{Mo} / \mathrm{Al}_{2} \mathrm{O}_{3}$ and $\mathrm{Ni}-\mathrm{Mo} / \mathrm{Al}_{2} \mathrm{O}_{3}$ catalysts by $\mathrm{NO}$ chemisorption, J. Catal. 84, 386 .

20 Maugé F., Duchet J.C., Lavalley J.C., Houssenbay S., Payen E., Grimblot J., Kasztelan S. (1991) The sulphided state of nickel molybdenum catalysts supported on zirconia and aluminates, Catal. Today 10,561.

21 De la Rosa M.P., Texier S., Berhault G., Camacho A., Yacaman M.J., Mehta A., Fuentes S., Montoya J.A., Murrieta F., Chianelli R.R. (2004) Structural studies of catalytically stabilized model and industrial-supported hydrodesulfurization catalysts, J. Catal. 225, 288.

22 Raybaud P. (2007) Understanding and predicting improved sulfide catalysts: Insights from first principles modeling, Appl. Catal. A: Gen. 322, 76.

23 Paul J.-F., Cristol S., Payen E. (2008) Computational studies of (mixed) sulfide hydrotreating catalysts, Catal. Today 130, 139.

24 Raybaud P., Hafner J., Kresse G., Kasztelan S., Toulhoat H. (2000) Structure, Energetics, and Electronic Properties of the Surface of a Promoted $\mathrm{MoS}_{2}$ Catalyst: An ab Initio Local Density Functional Study, J. Catal. 190, 128.

25 Schweiger H., Raybaud P., Toulhoat H. (2002) Promoter Sensitive shapes of Co(Ni)MoS Nanocatalysts in Sulfo-reductive Conditions, J. Catal. 212, 33.

26 Byskov L.S., Hammer B., Norskov J.K., Clausen B.S., Topsoe H. (1997) Sulfur bonding in $\mathrm{MoS}_{2}$ and Co-Mo-S structures, Catal. Lett. 47, 177.

27 Lauritsen J.V., Nyberg, M., Nørskov J.K., Clausen B.S., Topsøe H., Lægsgaard E., Besenbacher F. (2004) Hydrodesulfurization reaction pathways on $\mathrm{MoS}_{2}$ nanoclusters revealed by scanning tunneling microscopy, J. Catal.224, 94.

28 Lauritsen J.V., Kibsgaard J., Olesen G.H., Moses P.G., Hinnemann B., Helveg S., Nørskov J.K., Clausen B.S., Topsøe H., Laegsgaard E., Besenbacher F. (2007) Location and coordination of promoter atoms in Co- and Ni-promoted $\mathrm{MoS}_{2}$-based hydrotreating catalysts, J. Catal. 249, 220.

29 Daudin A., Brunet S., Perot G., Raybaud P., Bouchy C. (2007) Transformation of a model FCC gasoline olefin over transition monometallic sulfide catalysts, J. Catal. 248, 111.

30 Daudin A., Lamic A.F., Perot G., Brunet S., Raybaud P., Bouchy C. (2008) Microkinetic interpretation of HDS/HYDO selectivity of the transformation of a model FCC gasoline over transition metal sulfides, Catal. Today 130, 221.

31 Brunet S., Mey D., Perot G., Bouchy C., Diehl F. (2005) On the hydrodesulfurization of FCC gasoline: a review, Appl. Catal. A: Gen. 278, 143.
32 Mey D., Brunet S., Canaff C., Maugé F., Bouchy C., Diehl F. (2004) HDS of a model FCC gasoline over a sulfided $\mathrm{CoMo} / \mathrm{Al}_{2} \mathrm{O}_{3}$ catalyst: Effect of the addition of potassium, $J$. Catal. 227, 436.

33 Lamic A.F., Daudin A., Brunet S., Legens C., Bouchy C., Devers E. (2008) Effect of $\mathrm{H}_{2} \mathrm{~S}$ partial pressure on the transformation of a model FCC gasoline olefin over unsupported molybdenum sulfide-based catalysts, Appl. Catal. A: Gen.344, 198.

34 Choi J.-S., Mauge F., Pichon C., Olivier-Fourcade J., Jumas J.C., Petit-Clair C., Uzio D. (2004) Alumina-supported cobalt-molybdenum sulfide modified by tin via surface organometallic chemistry: application to the simultaneous hydrodesulfurization of thiophenic compounds and the hydrogenation of olefins, Appl. Catal. A: Gen. 267, 203.

35 Cristol S., Paul J.F., Payen E., Bougeard D., Hutschka F., Clemendot S. (2004) DBT derivatives adsorption over molybdenum sulfide catalysts: a theoretical study, J. Catal. 224, 138.

36 Cristol S., Paul J.F., Schovsbo C., Veilly E., Payen E. (2006) DFT study of thiophene adsorption on molybdenum sulfide, $J$. Catal.239, 145 .

37 Raybaud P., Hafner J., Kresse G., Toulhoat H. (1998) Adsorption of thiophene on the catalytically active surface of $\mathrm{MoS}_{2}$ : An ab initio local-density-functional study, Phys. Rev. Lett. 80, 1481.

38 Sun M., Nelson A.E., Adjaye J. (2006) Adsorption Thermodynamics of Sulfur- and Nitrogen-containing Molecules on NiMoS: A DFT Study, Catal. Lett. 109, 133.

39 Orita H., Uchida K., Itoh N. (2004) A volcano-type relationship between the adsorption energy of thiophene on promoted $\mathrm{MoS}_{2}$ cluster-model catalysts and the experimental HDS activity: $a b$ initio density functional study, Appl. Catal.A: Gen. 258, 115.

40 Weber T., Van Veen J.A. (2008) A density functional theory study of the hydrodesulfurization reaction of dibenzothiophene to biphenyl on a single-layer NiMoS cluster, Catal. Today 130, 170.

41 Sun M.Y., Nelson A.E., Adjaye J. (2005) Adsorption and hydrogenation of pyridine and pyrrole on NiMoS: an ab initio densityfunctional theory study, J. Catal. 231, 223.

42 Sun M.Y., Nelson A.E., Adjaye J. (2005) First principles study of heavy oil organonitrogen adsorption on NiMoS hydrotreating catalysts, Catal. Today 109, 49.

43 Todorova T., Prins R., Weber T. (2005) A density functional theory study of the hydrogenolysis reaction of $\mathrm{CH}_{3} \mathrm{SH}$ to $\mathrm{CH}_{4}$ on the catalytically active (100) edge of $2 \mathrm{H}-\mathrm{MoS}_{2}$, J. Catal. 236, 190.

44 Moses P.G., Hinnemann B., Topsoe H., Norskov J. (2007) The hydrogenation and direct desulfurization reaction pathway in thiophene hydrodesulfurization over $\mathrm{MoS}_{2}$ catalysts at realistic conditions: A density functional study, J. Catal. 248, 188-203.

45 Krebs E., Silvi B., Daudin A., Raybaud P. (2008) A DFT study of the origin of the HDS/HydO selectivity on $\mathrm{Co}(\mathrm{Ni}) \mathrm{MoS}$ active phases, J. Catal. 260, 276.

46 Scheffler M., Dabrowski J. (1988) Parameter-free calculations of total energies, interatomic forces and vibrational entropies of defects in semiconductors, Philos. Mag. A 58, 107.

47 Quian G.X., Martin R.M., Chadi D.J. (1988) First-principles study of the atomic reconstructions and energies of Ga- and Asstabilized GaAs(100), Phys. Rev. B 38 11, 7649.

48 Kadas K., Kern G., Hafner J. (1998) Ab initio studies of the (111) and (-1 -1 -1) surfaces of cubic BN: Structure and energetics, Phys. Rev. B $\mathbf{5 8 ~ 2 3 , 1 .}$

49 Wang X.-G., Weiss W., Shaikhutdinov Sh.K., Ritter M., Petersen M., Wagner F., Schlögl R., Scheffler M. (1999) The Hematite $\left(\alpha-\mathrm{Fe}_{2} \mathrm{O}_{3}\right)(0001)$ Surface: Evidence for Domains of Distinct Chemistry, Phys. Rev. Lett. 81, 1038. 
50 Reuter K., Stampfl C., Scheffler M. (2005) Handbook of Materials Modeling - Ab initio Thermodynamics and Statistical Mechanics of Surface Properties and Functions, Yip S. (Ed.), Springer, Berlin, Vol. 1.

51 Raybaud P., Costa D., Corral Valero M., Arrouvel C., Digne M., Sautet P., Toulhoat H. (2008) First principles surface thermodynamics of industrial supported catalysts in working conditions, $J$. Phys. Cond. 20, 064235.

52 Raybaud P., Hafner J., Kresse G., Kasztelan S., Toulhoat H. (2000) Ab Initio Study of the $\mathrm{H}_{2}-\mathrm{H}_{2} \mathrm{~S} / \mathrm{MoS}_{2}$ Gas-Solid Interface: The Nature of the Catalytically Active Sites, J. Catal.189, 129.

53 Digne M., Sautet P., Raybaud P., Euzen P., Toulhoat H. (2002) Hydroxyl groups on gamma Alumina Surfaces: a DFT Study, $J$. Catal. 211, 1.

54 Arrouvel C., Breysse M., Toulhoat H., Raybaud P. (2005) A density functional theory comparison of anatase $\left(\mathrm{TiO}_{2}\right)$ - and $\gamma$ $\mathrm{Al}_{2} \mathrm{O}_{3}$-supported $\mathrm{MoS}_{2}$ catalysts, J. Catal. 232, 161 .

55 Costa D., Arrouvel C., Breysse M., Toulhoat H., Raybaud P. (2007) Edge wetting effects of $\gamma-\mathrm{Al}_{2} \mathrm{O}_{3}$ and anatase- $\mathrm{TiO}_{2}$ supports by $\mathrm{MoS}_{2}$ and CoMoS active phases: A DFT study, $J$. Catal. 246, 325.

56 Perdew J.P., Wang Y. (1992) Accurate and simple analytic representation of the electron-gas correlation energy, Phys. Rev. B 45, 13244.

57 Hohenberg P., Kohn W. (1964) Inhomogeneous Electron, Gas, Phys.Rev. B 136, 864.

58 Kohn W., Sham L.J. (1965) Self-Consistent Equations Including Exchange and Correlation Effects, Phys. Rev. A 140, 1133.

59 Kresse G., Furthmüller J. (1996) Efficiency of ab-initio total energy calculations for metals and semiconductors using a planewave basis set, Comput. Mater. Sci. 6, 15.

60 Kresse G., Joubert D. (1999) From ultrasoft pseudopotentials to the projector augmented-wave method, Phys.Rev.B 59, 1758.

61 Byskov L.S., Nørskov J.K., Clausen B.S., Topsøe H. (1999) DFT Calculations of Unpromoted and Promoted $\mathrm{MoS}_{2}$-Based Hydrodesulfurization Catalysts, J. Catal. 187, 109.

62 Sun M., Nelson A.E., Adjaye J. (2004) On the incorporation of nickel and cobalt into $\mathrm{MoS}_{2}$-edge structures, J. Catal. 226, 32.

63 Krebs E., Silvi B., Raybaud P. (2008) Mixed sites and promoter segregation: A DFT study of the manifestation of Le Chatelier's principle for the $\mathrm{Co}(\mathrm{Ni}) \mathrm{MoS}$ active phase in reaction conditions, Catal. Today 130, 160.

64 Okamoto Y., Kawano M., Kawabata T., Kubota T., Hiromitsu I. (2005) Structure of the Active Sites of Co-Mo Hydrodesulfurization Catalysts as Studied by Magnetic Susceptibility Measurement and NO Adsorption, J. Phys. Chem. $B$ 109, 288.

65 Lauritsen J.V., Bollinger M.V., Lægsgaard E., Jacobsen K.W., Nørskov J.K., Clausen B.S., Topsøe H., Besenbacher F. (2004) Atomic-scale insight into structure and morphology changes of $\mathrm{MoS}_{2}$ nanoclusters in hydrotreating catalysts, J. Catal. 221, 510.

66 Topsøe H., Clausen B.S., Topsøe N.-Y., Pedersen K.J., Niemann W., Müller A., Bögge H., Lengeler B. (1987) Inorganic cluster compounds as models for the structure of active sites in promoted hydrodesulphurization catalysts, J. Chem. Soc. Farad. T. $1 \mathbf{8 3}, 2157$.
67 Bouwens S.M.A.M., Veen J.A.R. van, Koningsberger D.C., Beer V.H.J. de, Prins R. (1991) EXAFS determination of the structure of cobalt in carbon-supported cobalt and cobalt-molybdenum sulfide hydrodesulfurization catalysts, J. Phys. Chem. 95, 123.

68 Niemann W., Clausen B.S., Topsoe H. (1990) X-Ray absorption studies of the Ni environment in Ni-Mo-S, Catal. Lett. 4, 355.

69 Louwers S.P.A, Prins R. (1992) Ni EXAFS studies of the Ni-Mo-S structure in carbon-supported and alumina-supported Ni-Mo catalysts, J. Catal. 133, 94.

70 Curie M.P. (1885) Sur la formation des cristaux et sur les constantes capillaires de leurs différentes faces, B. Soc. Min. France $\mathbf{8}, 145$.

71 Wulff G. (1901) Zur Frage der Geschwindigkeit des Wachstums und der Auflösung der Krystallflächen, Z. Kristallogr. 34, 449.

72 Gandubert A., Krebs E., Legens C., Costa D., Guillaume D., Raybaud P. (2008) Optimal promoter edge decoration of CoMoS catalysts: A combined theoretical and experimental study, Catal. Today 130, 149.

73 Gandubert A., Legens C., Guillaume D., Rebours S., Payen E. (2007) X-ray photoelectron spectroscopy surface quantification of sulfided CoMoP catalysts - Relation between activity and promoted sites - Part I: Influence of the Co/Mo ratio, Oil Gas Sci. Technol. - Rev.IFP 62, 79.

74 Travert A., Dujardin C., Maugé F., Veilly E., Cristol S., Paul J.F., Payen E. (2006) CO Adsorption on CoMo and NiMo Sulfide Catalysts: A Combined IR and DFT Study, J. Phys. Chem. B 110, 1261-1270.

75 Logadottir A., Rod T.H., Nørskov J.K., Hammer B., Dahl S., Jacobsen C.J.H. (2001) The Bronsted-Evans-Polanyi Relation and the Volcano Plot for Ammonia Synthesis over Transition Metal Catalysts, J. Catal. 197, 229.

76 Raybaud P., Hafner J., Kresse G., Toulhoat H. (1997) Ab initio density functional studies of transition-metal sulphides: I. Crytal structure and cohesive properties, J. Phys. Cond.9, 11085.

77 Toulhoat H., Raybaud P., Kasztelan S., Kresse G., Hafner J. (1999) Transition metals to sulfur binding energies relationship to catalytic activities in HDS: back to Sabatier with first principle calculations, Catal. Today 50, 629.

78 Toulhoat H., Raybaud P. (2003) Kinetic interpretation of catalytic activity patterns based on theoretical descriptors, J. Catal. 216, 63.

79 Sabatier P. (1911) Hydrogénations et déshydrogénations par catalyse, Berichte der Deutschen Chem. Gesellschaft 44, 2001.

80 Krebs E., Silvi B., Raybaud P. (2009) Topological analysis of the interactions between organic molecules and $\mathrm{Co}(\mathrm{Ni}) \mathrm{MoS}$ catalytic active phase, J. Comput. Theoretical Chem. DOI: $10.1021 / \mathrm{ct} 800344 \mathrm{r}$.

81 Miller J.T., Reagan W.J., Kaduk J.A., Marshall C.L., Kropf A.J. (2000) Selective Hydrodesulfurization of FCC Naphtha with Supported $\mathrm{MoS}_{2}$ Catalysts: The Role of Cobalt, J. Catal. 193, 123-131.

82 Marchand K., Legens C., Guillaume D., Raybaud P. (2009) A rational comparison of the optimal promoter edge decoration of HDT Ni MoS vs CoMoS catalysts, Oil Gas Sci. Technol., this issue.

Final manuscript received in January 2009 Published online in April 2009

Copyright (C) 2009 Institut français du pétrole

Permission to make digital or hard copies of part or all of this work for personal or classroom use is granted without fee provided that copies are not made or distributed for profit or commercial advantage and that copies bear this notice and the full citation on the first page. Copyrights for components of this work owned by others than IFP must be honored. Abstracting with credit is permitted. To copy otherwise, to republish, to post on servers, or to redistribute to lists, requires prior specific permission and/or a fee: Request permission from Documentation, Institut français du pétrole, fax. +33147527078 , or revueogst@ifp.fr. 